\title{
Designing Digital Solutions for Preserving Penan Sign Language: A Reflective Study
}

\author{
Tariq Zaman, ${ }^{1}$ Alvin W. Yeo, ${ }^{1}$ and Geran Jengan ${ }^{2}$ \\ ${ }^{1}$ Institute of Social Informatics and Technological Innovations, Universiti Malaysia Sarawak, 94300 Kota Samarahan, Malaysia \\ ${ }^{2}$ Long Lamai, Sarawak, Malaysia \\ Correspondence should be addressed to Tariq Zaman; zamantariq@gmail.com
}

Received 29 October 2015; Accepted 7 March 2016

Academic Editor: Thomas Mandl

Copyright (c) 2016 Tariq Zaman et al. This is an open access article distributed under the Creative Commons Attribution License, which permits unrestricted use, distribution, and reproduction in any medium, provided the original work is properly cited.

\begin{abstract}
Oroo' is a language of nomadic Penans in the rainforests of Borneo and the only way of asynchronous communication between nomadic groups in the forest journey. Like many other indigenous languages, the Oroo' language is also facing imminent extinction. In this paper, we present the research process and reflections of a multidisciplinary community-based research project on digitalizing and preserving the Oroo' sign language. As a methodology for project activities, we are employing Participatory Action Research in Software Development Methodology Augmentation (PRISMA). Preliminary results show a general interest in digital contents and a positive impact of the project activities. In this paper, we present scenario of a research project that is retooled to fit the need of communities, informing language revitalization efforts and assisting with the evolution of community-based research design.
\end{abstract}

\section{Introduction}

Indigenous peoples have the right to revitalize, use, develop and transmit to future generations their histories, languages, oral traditions, philosophies, writing systems and literatures, and to designate and retain their own names for communities, places and persons. (United Nations Draft Declaration of the Rights of Indigenous Peoples, 1993)

There are estimated 40 percent of languages that are endangered. A language is in danger when its speakers no longer pass it on to the next generation. Languages are far more threatened than birds (11\% threatened, endangered, or extinct), mammals (18\%), fish (5\%), or plants (8\%). According to Ethnologue, $84 \%$ of the 46 living languages in Sarawak have less than 10,000 speakers [1]. Besides spoken and written languages much less documented and well-known are the sign and secret languages of rainforest inhabitants, which are made out of combinations of twigs, leaves, and other jungle products. Penans' sign language Oroo' is one of the examples. Oroo' is an extremely sophisticated asynchronous signage language of the nomadic Penans in the rainforests of Malaysian Borneo. The Oroo' signs are made out of rainforest materials, such as twigs, branches, and leaves, and attached to the signage stick. Through different combinations of signs, various messages and narratives are constructed, such as call for help, warnings of danger (snakes, old branches, and enemies), instructions (meeting points and times), and information about whereabouts of food, animals, humans, and houses.

According to Moseley, "The loss of indigenous languages is also detrimental to biodiversity, as traditional knowledge of nature and the universe, spiritual beliefs and cultural values expressed in indigenous languages provide time-tested mechanisms for the sustainable use of natural resources and management of ecosystems, which have become more critical with the emergence of urgent new challenges posed by climate change" [2]. Oroo' is a living cultural heritage of the Penan which, from a historical, political, social, and scientific perspective, is of extreme value to our society. It is a unique example of convergent relationship between cultural diversity, language, and biodiversity of Borneo. There is thus a need to document, preserve, and sustain this language. However, literature referring to Oroo' is extremely sparse.

In 2014, the Institute of Social Informatics and Technological Innovations (ISITI), Universiti Malaysia Sarawak (UNIMAS), and Long Lamai community with the support 
of Information Society Innovation Fund Asia (ISIF/APNIC) initiated a project to digitalize and preserve the Oroo' In this paper, we present the background, research method adopted, and the reflective analysis of the documentation and digitalization of Oroo' signs project. The first part of the paper discusses a background of the partner communities and the Penan sign language Oroo' (hereinafter referred to as "Oroo"). We then provide the research and project context as well as our documentation and digitalization efforts of Oroo', the sign language of the Penan. We conclude the paper with our reflections and contributions to the field of local content creation under the theme of "Society Transformation through Social Innovation Systems."

\section{Background}

The study has been guided by Long Lamai and Long Kerong, remote and rural Penan villages in upper Baram region of Malaysian Borneo. From the nearest city, Miri, the journey to Long Lamai comprises one-and-a-half-hour Twin Otter flight or a 10-hour 4-wheel drive journey over logging road and an hour's boat ride upriver. The community in Long Lamai consists of approximately 598 individuals and 116 households. Long Kerong consists of 40 households with approximately 120 Penan inhabitants. The journey to Long Kerong comprises a 5-hour 4-wheel drive over logging road from Miri to Lio Matoh, and a 3-hour boat ride upriver to Long Kerong. The communities of Long Lamai and Long Kerong are Penans from similar nomadic group living in the same environment. They have settled down in different locations (Figure 1) in the early 1950s.

In terms of access to basic amenities, Long Lamai has a primary school, telecentre, and limited access to mobile coverage and electricity supply from microhydro project [3]. Long Kerong has none of these facilities and their lifestyle is more traditional and less influenced by outside World. Due to the traditional lifestyle of Long Kerong, the elders of the village are considered more knowledgeable (about nomadic lifestyle) than their counterparts. Both of the communities are dependent on forest for their livelihoods and for hunting and gathering. The journey to the forest is called Toro [4]. The activities of Toro start from leaving the Lamin Toto (a house in the village) and finding a place in the forest that has enough food such as fruit trees, fish in nearby river, sago plants, and animals for hunting.

In the Toro journey, a Penan family travels in two groups. The journey is led by the young and physically strong members of the family, who find a suitable place and establish the Lamin Toro (or a traditional temporary hut in the forest). Subsequently, the elders and children follow the group on the same route and join them at the place of Lamin Toro.

During Toro journey, the leading group communicates with the following group by making Oroo' signs. The signs convey messages such as the location of the Lamin Toro, path and directions of group movement, and the number of individuals in the group.

The rapid change in the Penans' way of life (from nomadic to semipermanent or permanent settlement) has largely

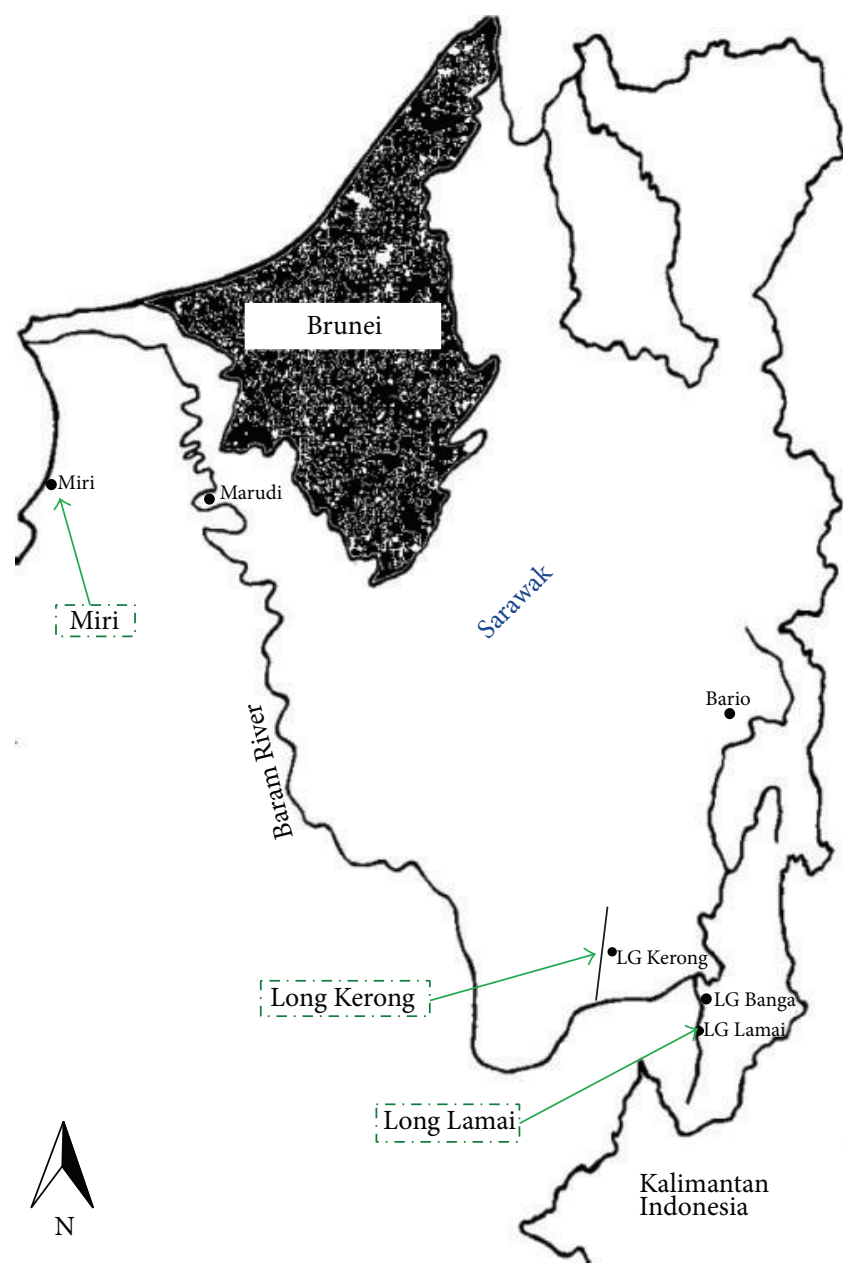

Figure 1: Location of Longa Lamai, Long Kerong, and Miri in the state of Sarawak, Malaysia.

accounted for the loss of their rich cultural, botanical, and social knowledge bases. With the permanent and semipermanent settlements they are less dependent on the forest as food source and spend less time in the forest. Hence, they are rapidly losing indigenous knowledge of the plants and Oroo'. As a result of rapid loss of tradition, there has been an upsurge in interest in the recording of oral histories, oral accounts, and oral literature.

In 2009, after the inauguration of eLamai telecentre, Long Lamai community has access to ICTs and Internet. In initial stage (2009-2010), the telecentre mainly worked as a communication hub. From 2010 onward, community has opened the doors for ecotourism services and using Internet as a means to market their tourism products, highlight local development issues, document indigenous botanical knowledge, and create an online Penan language dictionary and ehealth system $[5,6]$. The community elders also acknowledge the growing interest of their young generation in ICTs and the role of technology in bridging the social and cultural intergenerational gap in Long Lamai. There is general consensus in the community that new approaches and measures that combine traditional and modern tools/methods in an appropriate way can address this challenge of cultural 
extinction. From the beginning of the project, the project partners are optimistic about the potential role of ICTs in digitalizing and preserving Oroo. However, before we embark on identifying ways to digitalize and preserve the Oroo, a review of literature and understanding of the Oroo' signs are warranted.

\section{Literature Review}

3.1. Sign and Secret Languages. The sign and secret languages of the indigenous people have been the basis for an internationally recognised vocabulary of bush craft signs or modern survival signs. The signs are similar to those used by the colonial military troops originally and the scouts later on [7]. An example of the digitalized version of an indigenous signage is the private CyberTracker project in southern Africa. The project introduces the important traditional knowledge of the San (Bushmen) about the migratory movements of wild animals accessible by means of handheld portable computers. To date, more than 120 trackers have become acquainted with the new technology such as ICTs and mobile devices. San's skills are benefiting the national parks, which, in this way, can reliably monitor their game stock. The project has also led to a significant decline in poaching [8].

In an attempt to read up more about Oroo' on the internet, we only found fragmented and limited information on the socalled forest sign language of Borneo, but without mentioning the term Oroo'. According to BBC, "The Penan like their secrets and have a complex sign language for use in the forest. A bent twig stuck in the trail may simply say 'we went this way', but complex arrangements of cut twigs, sticks and folded leaves can tell the Penan anything from the state of the hunting locally to whether the person leaving the sign is in a good mood" [9]. Furthermore, "whenever the Penan 'molong' a fruit tree, they place an identifying sign on it, a wooden marker or a cut of a machete. It is a notice of effective ownership and a public statement that the natural product is to be preserved for harvesting at a later time" [10]. The "molong" sign is one of many Oroo' signs. According to Curtis, the Penan "maintains a dialogue with others by means of arranging sticks, branches, and leaves to convey messages. These signs are virtually invisible or unintelligible to the uninitiated, and can track a journey in great detail. They can be used to tell other tribes of their travel route, indicate whether food is available, identify burial sites and alert others of danger" [11].

The review shows that theoretical literature of Oroo' is extremely sparse. To the best of our knowledge, neither a formal documentation process nor a digitalizing effort has been initiated for preservation of Oroo'. As such, the goal of this paper would be to provide a methodology to allow the digitalization and preservation of a signage language, which is Oroo'.

3.2. Digitizing Indigenous Languages. Many initiatives of language preservation have flourished over the last decade. Technology has been considered as a magic tool and promoting usage of language in daily life was less emphasised. Thus, recently more initiatives aimed at developing technologies for supporting practical solutions. A good demonstration of such an endeavor is "The Yanomami Intercultural Education Program" where indigenous communities were involved in the development of digital educational material thereby enhancing the literacy rate in indigenous languages [12]. While the examples are many, relatively few indigenous "nonwritten" languages of communication systems are digitized. For example, sand drawings are a medium of communication practiced by the Native Americans in the Southwestern United States, by Tibetan and Buddhist monks, as well as Australian Aborigines sand drawing. In this art, the design is drawn in one continuous motion by fingers tracing out the intricate and geometric designs on the ground or sand [13]. As a preservation movement in 2011, the Vanuatu Cultural Centre digitized more than 3000 audiotapes, 1000 VHS and other video formats, and about 3000 photographs. The other examples are the Dennis Be Bel developed smoke messaging service iPhone add-on hardware case that releases puffs of smoke to communicate securely with others [14] and Busuu, a social network Website (with downloadable app) for learning Silbo Gomero, the whistle language of La Gomera. Although whistled languages can be found around the world, they are rare, and few are likely to survive in the long term [15].

\section{Methodology}

For external observers (researchers), some of the variables related to local culture are easy to explore such as written and spoken languages, format of dates and numbers, character sets, and notations. Such variables, according to the Iceberg Model presented by Hoft [16], are visible and "above the surface." The software engineers need to closely engage with the end-users to comprehensively understand the needs and requirements. Therefore, the community/user centred approaches such as participatory design (PD) and respectful design [17] and community-based codesign [18] have received much attention since the last decade [19]. These approaches emphasise providing equal space for dialogue to "designers" and "nondesigners" so that the end-users can be a part of the whole design process such as problem exploration, goal setting, tasks distribution, understanding of cultural differences, and suggesting a solution which is frugal and better informed by the local context and indigenous knowledge.

For this project, we are employing Participatory Action Research in Software Development Methodology Augmentation (PRISMA) [20]. PRISMA is a combination of participatory action research methodology and software development methodology. PRISMA emphasises community active participation in the development of technologies such as software which are to be used by indigenous communities. Our research group has built long-term collaboration with Long Lamai community with regard to the deployment of ICTs for appropriate usage [21]. In the initial stage of the project, we engaged the Long Lamai community in detailed discussions to establish the importance of Oroo' and the need of digitalization and preservation processes. One of our coauthors is a member of Long Lamai community 

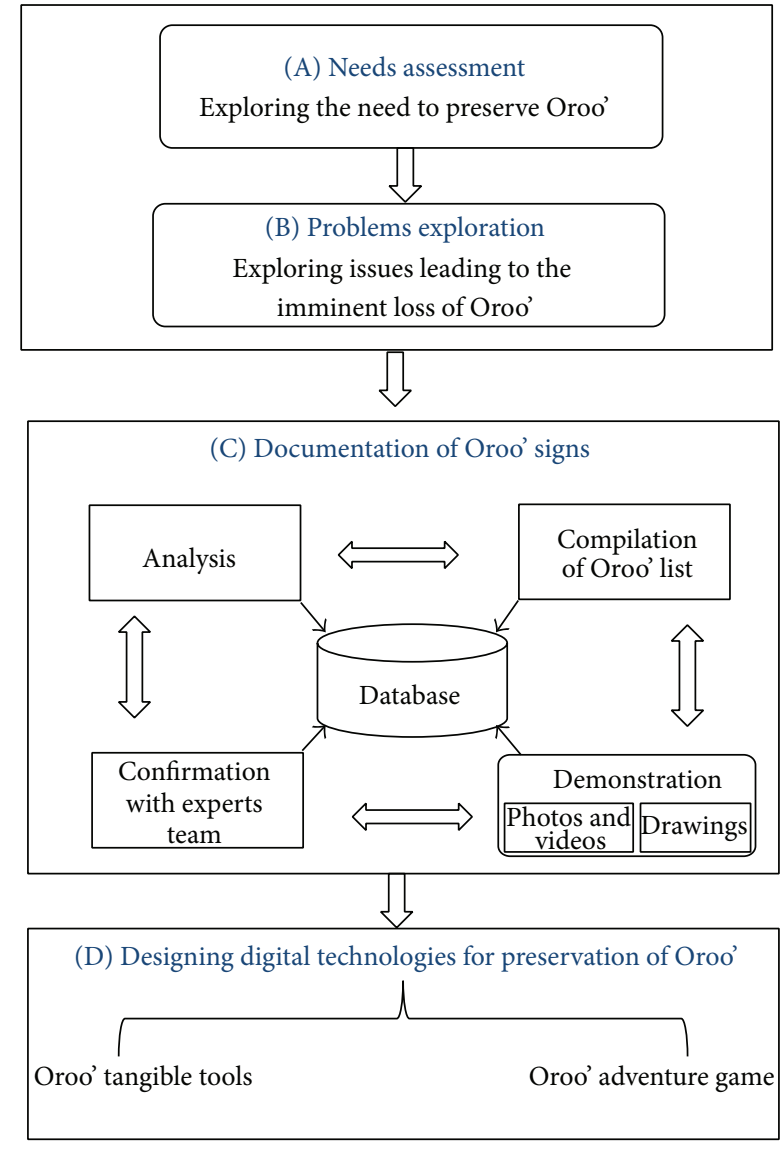

FIgURE 2: Research process.

and community selected local champion for the project. The community members agreed to be referred to by their actual names in the research publications.

The following section describes briefly the research process (Figure 2).

(A) Need Assessment. We assessed the need of the documentation process and henceforth the social, economic, cultural, and scientific implications of the project.

(B) Problems Exploration. In this stage of the research, we mainly probed the issues leading to the imminent loss of Oroo.

(C) Documentation of Oroo' Signs. In this stage, we commenced written, photo, and video documentation and analysis process of Oroo'.

(D) Designing Digital Technologies for Preservation of Oroo' Language. After documentation and analysis, we formulated our strategies and designed digital tools for preservation of Oroo' sign language.

\section{Results}

5.1. Stage A: Need Assessment. During meetings with community (Figure 3 ), we observed an extreme concern about

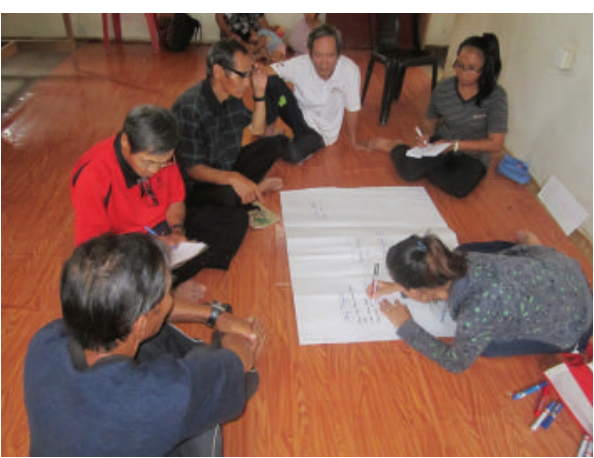

Figure 3: Discussion within community group.

the extinction of Oroo' language. According to Taman Pita (approximately 90 years old), "we don't know how the children will survive in the forest if they don't learn language of forest (Oroo')." The village assistant headman Uda (70 years old) said that he learnt many Oroo' from his elders when they led him in Toro journey but today he does not remember all of them. We conducted a survey with 80 Penan youths and found that the individuals under age of 20 years know the meaning of 4 Oroo' signs, between the ages of 20 and 30 years know 8 Oroo' signs, and above the age of 50 years know more than 40 Oroo' signs. The figures indicate that young members of Long Lamai community are rapidly losing this rich cultural heritage of Penans.

To make Oroo' signs, it is important to have ample knowledge of forest, an accretion of experiences of seasons, plants, river, creatures, and landscape of the forests. The extinction of Oroo' may lead to extinction of their unique ways of knowing, living, and identity. The Penan way of life is already in the very process of being forgotten under pressure from the dominant cultures [22].

5.2. Stage B: Problems Exploration. We conducted a group discussion (Figure 3 ) in order to identify the main impediments for Penan youth in learning and practicing Oroo' signs. The identified three main causes are as follows:

(I) Young community members are not traveling frequently in the forest.

(II) Now everyone knows writing script languages so why should they use Oroo'

(III) They have mobile devices so why should they communicate with Oroo.'

To address these issues, the project team discussed and agreed on creating Oroo' training material (digital and printed) and to introduce Oroo' trail hunt, a tourism activity.

5.3. Stage C: Documentation of Oroo' Signs. From March 2014 to August 2015, we conducted 15 forest visits in Long Lamai and Long Kerong. Each visit was led by few community elders (Oroo' experts) and a translator and followed by researchers (Figure 4). In Long Lamai, the objectives of the forest visits were to collect photos and drawings of Oroo' signs and record 


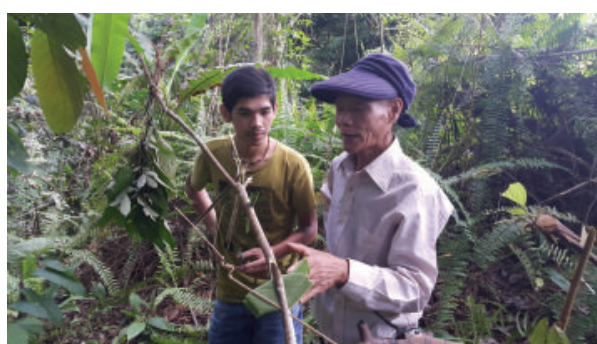

(a)

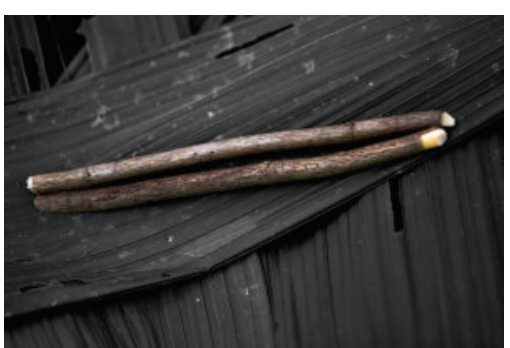

(b)

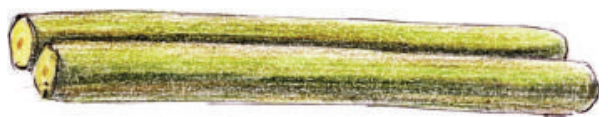

(c)

FIgURe 4: (a) Forest visit guided by Oroo' expert. (b) Photo of Oroo' sign. (c) Drawing of Oroo' sign.

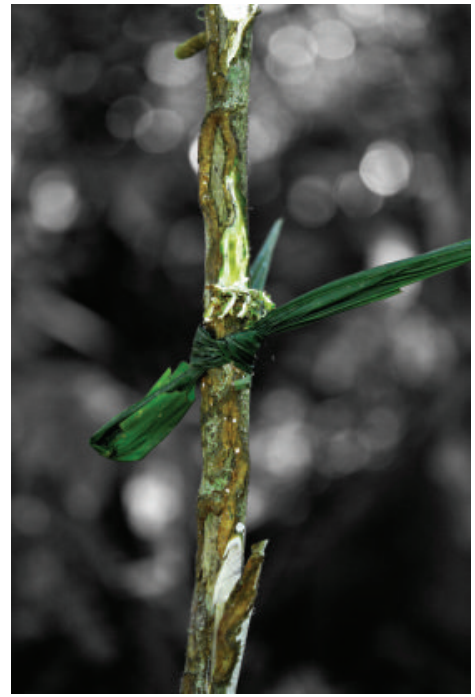

(a)

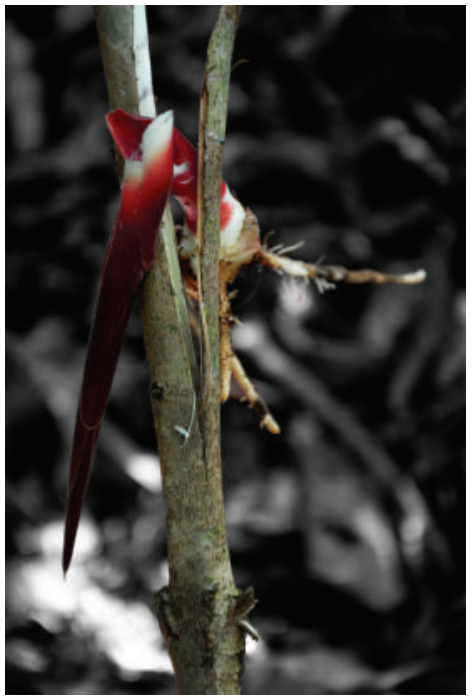

(b)

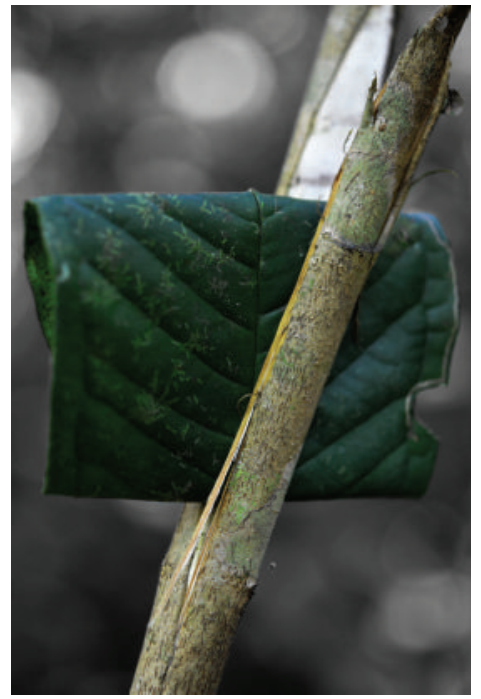

(c)

FIGURE 5: (a) I am badly injured. (b) Danger ahead. (c) I am hungry.

the descriptions and construction process of each signs. The field visits in Long Kerong were mainly organized for reconfirmation of the collected information in Long Lamai. A local artists group was engaged to draw the Oroo' signs and to compile an Oroo' drawing repository (Figure 4). So far we have compiled a detailed database of 55 signs.

The Oroo' signs convey asynchronous messages to the group of people who are following. The Oroo' signage is made out of rainforest materials, such as twigs, branches, and leaves. Through different combinations of these elements, new meanings could then be constructed. The language expresses indigenous conceptualisations and circumstances of the people within their context such as a call for help or danger ahead from a falling tree branch or stinging bees (Figure 5). The language is dynamic and the signs are constructed on the spot thereby allowing extreme flexibility. The language follows a set of rules so there is a strong relationship between the signs, materials used for creating the sign, the representation of the objects in the signs, and meaning of the signs. The signs have the ability to communicate complex unified messages, with a possibility for embedding cryptic messages. The signs represent a variety of ideas such as order (duration, length), alerts (danger), usage of common symbols (e.g., using a particular type of twig or material), information and whereabouts of creator of the message, context-specific information, and temporal and spatial data (over a trail).

\subsection{Stage D: Designing Digital Technologies for Oroo' Language} Preservation. Our target users of digital tools comprise two age groups. The first group is the children of age below 9 years and the second group is of age of 9-12 years. We designed distinct digital solutions for each age group.

5.4.1. Oroo' Tangible Tools. Capacitive sensing tangibles linked with 2D graphics were explored as a novel concept 


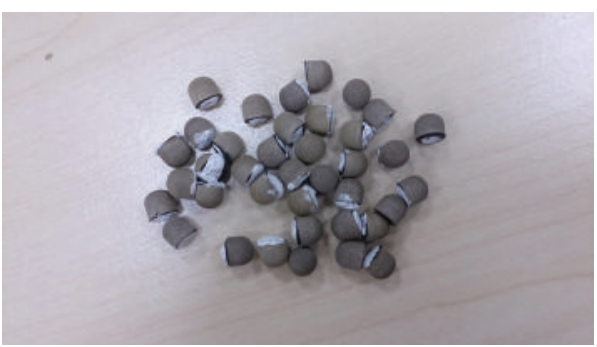

(a)

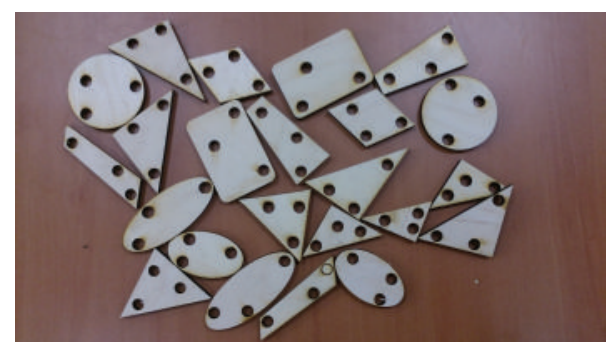

(b)

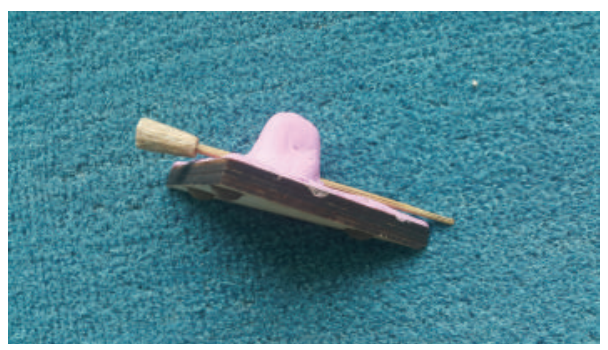

(c)

Figure 6: (a) Tips with clay. (b) Tangible baseplate. (c) A completed tangible.

for teaching Oroo' signs in this project. Tangible technologies that enable interaction on capacitive multitouch devices, such as iPad and iPhone, have proved their utility in a wide range of application scenarios including learning with toddlers [2325]. Capacitive multitouch surfaces work as a natural site for interaction with physical objects without requiring any hardware modifications.

Oroo' is a tangible language. The physical material used to construct an Oroo' is associated with the meaning of the Oroo' For example, Oroo' which indicates danger ahead (Figure 5) can be only made from a specific plant which is used as a remedy against dangerous insects' bites. By using tangibles, we demonstrated a closeness of representation between the Oroo' signs (physical objects) and the corresponding 2D graphics. The Oroo' tangibles were constructed out of a baseplate with touch points topped with a representation of Oroo' sign and a handle made of clay (Figure 6).

To make an Oroo' in the system, the user needs to press a tangible onto the display. As a result, the system retrieves a corresponding image and displays it directly under the tangible. The image can be rotated, erased, or moved to a new location. The system was evaluated as a collaborative learning tool in the village where 6 family groups consisting of, respectively, an Oroo' conversant parent and a child (age below 9 years) engaged with the tool [26] (Figure 7).

5.4.2. Oroo' Adventure Game. For the second group of children (9-12 years), we developed the Oroo' adventure game. There are two versions of the game; the first version consists of three stages [27] and the second version has four stages. The first stage describes Oroo' signs by using storytelling method. In second stage, the user then continues the game and spots the hidden signs scattered in the background picture of rainforest. In third stage, the user receives an Oroo' sign describing a specific animal and then uses his shooting skills to hunt the animal. In fourth stage, the game features a quiz that will give the player a few questions relating to the Oroo' signs and each correct answer from the quiz will increase the level of knowledge. By these interactive lessons, the game illustrates 26 Oroo' signs. The game software is in testing phase and in the first field, test results show a positive increase of interest and knowledge in users [27] (Figure 8).

\section{Reflections}

In the following sections, we present our reflections on our approach and its generalisability.

6.1. Inclusive and Participatory Processes. In the project, we follow a participatory design process that included more than fifteen community members over 18 months' period to guide focus group discussions, community meetings, and forest walks and review the translation and documentation (Figure 9). Elicitation of the meaning of Oroo' was a collaborative process that required mutual adaptation on the part of researcher and community guides. The acquisition of information process was embedded in the local and social understandings and we followed the community cultural protocols on Free, Prior and Informed Consent [28].

The local champion and community elders were part of the decision making process and guided the researchers on "what to document," "whom to ask," "where to ask," and "how to ask." One of the coauthors has been working with this community for the last 6 years so the process of community engagement was smooth. The role of the local champion is also very important. Researchers stayed in the community for a short term (3-4 days per visit) and some of the important tasks have been performed by the local champion 


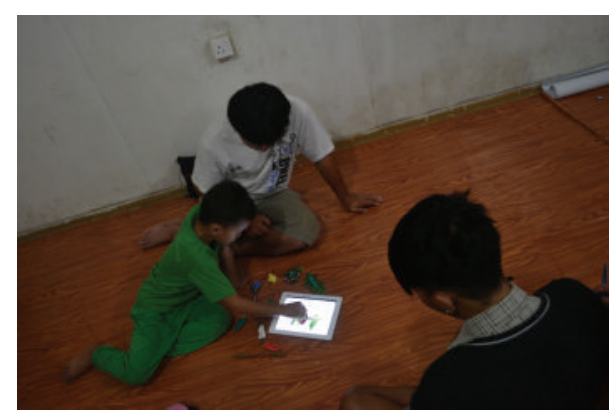

(a)

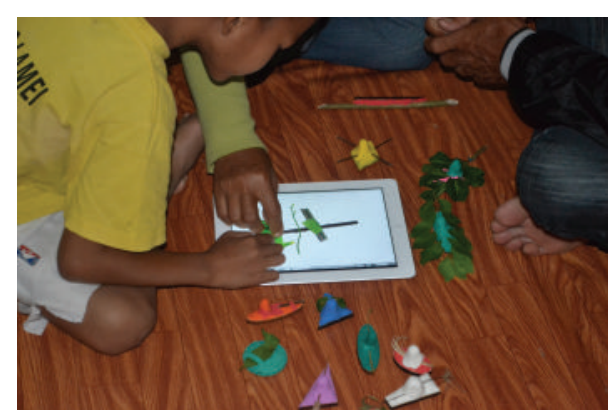

(b)

FIGURE 7: Users testing tangible system.

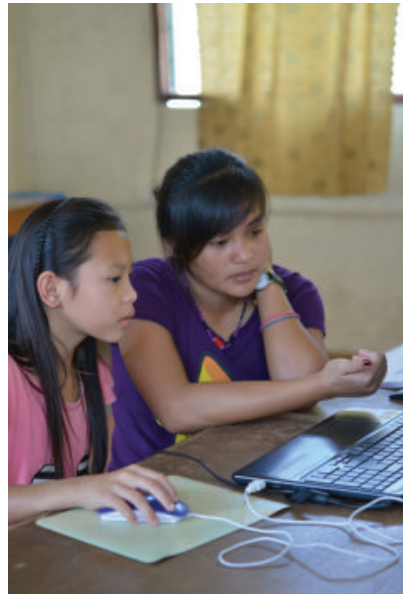

(a)

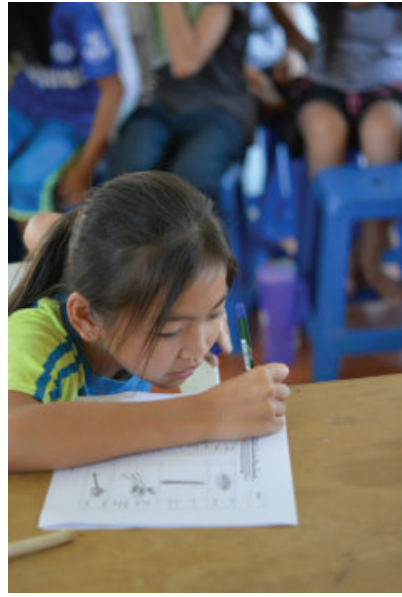

(b)
FIGURE 8: Users testing Oroo' adventure game.

and community members in absence of researchers such as preparing the list of Oroo' signs and reconfirmation of the translations and documentations.

6.2. Making Oroo' Products. When a target language is framed as content, the dynamic nature of language as a "system" is artificially frozen [29]. Oroo' is a living cultural heritage of the Penan. Penans are losing the "contents" of Oroo' because the "context" in which Oroo' is alive is dying. It is a language of the forest. Deforestation and changing lifestyle of the Penan youth have adverse effects on Oroo'. We realized that mere documentation process or digitization cannot sustain the Oroo' language's health unless we revive the sociocultural context in which the language can survive. Hence, we reframed and enhanced the goals of our project. In addition to documentation of the contents, we are promoting a cultural event, Oroo' trail hunt, as a tourism activity that would yield a product of Oroo'.

6.3. Oroo' Community of Practice. Today, the Penan youth are not frequently traveler of Toro journey which was the only established routine for learning Oroo' language.
The village elders have also forgotten many of the signs [27]. We found that the project produced a community of practice that emerged in collaboration within villages as well as between two villages (Figure 10). In initial stage of the project, we have five members of the community as part of the project team and they identified 32 signs for documentation. In second stage, the number of documented signs increased to 50 with the help of elders and experienced community members from Long Lamai. In third stage, few community members from Long Kerong have been engaged and they added five more signs to the list and shared more comprehensive knowledge rules and combinations of the signs.

6.4. New Oroo' Signs and Use in Contemporary Digital Space. According to International Expert Meeting on UNESCO Programme Safeguarding of Endangered Languages (2003), "Raising awareness about language loss and language diversity will only be successful when meaningful contemporary roles for minority languages can be established...meaningful contemporary roles include the use of these languages in everyday life." Oroo' is a language of Toro journey. The characters set of Oroo' language is limited to the expressions used in Toro journey. Today, many of the community members are using mobile phone for communication; however, there is very limited vocabulary for everyday communication in Oroo' language. For example, there is no sign for enquiry such as "how are you?" or "where are you?" However, these are the common text expressions in mobile communications. Hence, the elders of Long Lamai community are expanding the current set of signs and we are codesigning new and innovative communication tools for mobile devices.

\section{Conclusion}

The paper reflects our experience of aligning and synchronizing the research (researcher's interest) and development (community interest) issues. Even though most Penans are no longer nomadic, the elder generations still master Oroo' and express the desire for the next generations to engage with it. Thus, the main objective of the project is to systematically digitalize the complete signage language, which will provide 


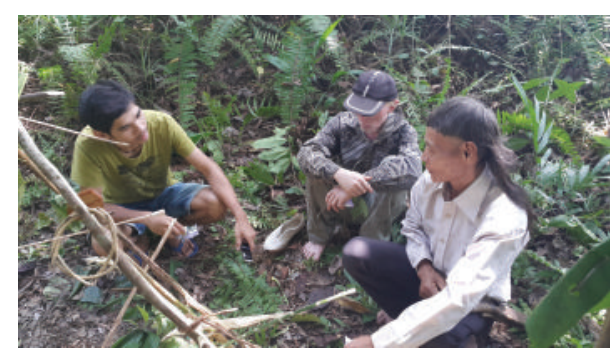

(a)

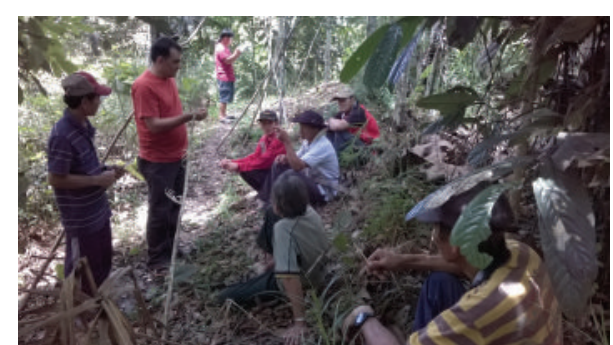

(b)

Figure 9: (a) Oroo' demonstration session in Long Kerong. (b) Oroo' demonstration session in Long Lamai.

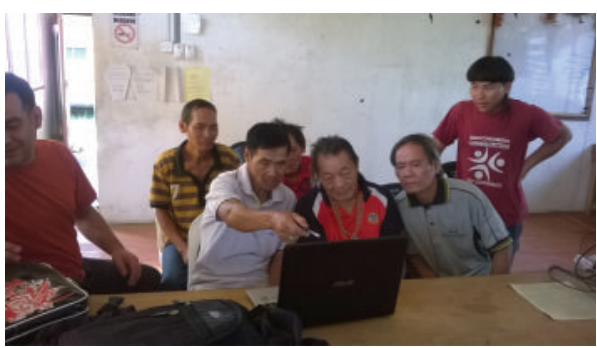

(a)

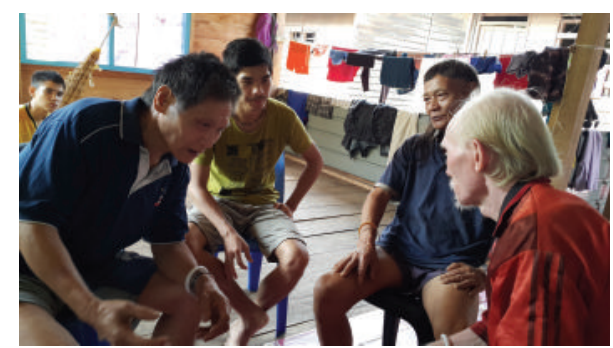

(b)

FIGURE 10: (a) Community discussion in Long Lamai. (b) Community discussion in Long Kerong.

the Penans with a modern technology to uphold and transfer their cultural heritage. The methodology of conducting research in indigenous communities, on sign language in this case, is another contribution of this research. Furthermore, it will also provide a data set of Oroo' to other researchers and from other disciplines.

\section{Competing Interests}

The authors declare that they have no competing interests.

\section{Acknowledgments}

The research was carried out with the aid of a grant from the Information Society Innovation Fund (ISIF) Asia and Universiti Malaysia Sarawak under Postdoctoral Fellowship Program. The authors thank all the community members who participated in one or another of our research activities.

\section{References}

[1] S. Saee, A. W. Yeo, and J. Wilfred, "Sarawak language technology (SaLT) initiative: preservation of sarawak ethnic languages," in Proceedings of the Borneo Research Council 9th Biennial International Conference (BRC '08), July 2008.

[2] C. Moseley, Atlas of the World's Languages in Danger, UNESCO, 2010.

[3] H. Winschiers-Theophilus, T. Zaman, K. L. Jensen, K. Rodil, and A. W. Yeo, "Mobile technologies for preservation of indigenous knowledge in rural communities," in Proceedings of the 8th International Conference on Information Technology in Asia (CITA '13), pp. 1-4, Kota Samarahan, Malaysia, July 2013.
[4] T. Zaman, A. Y. Wee, and N. Kulathuramaiyer, "Indigenous knowledge governance framework: scaffolding joint ICT developments in Long Lamai, Malaysia," in At the Intersection of Indigenous and Traditional Knowledge and Technology Design, N. J. Bidwell and H. Winschiers-Theophilus, Eds., p. 171, Informing Science Press, Santa Rosa, Calif, USA, 2015.

[5] E. Mit, C. W. Shiang, M. A. Khairuddin, and N. H. Borhan, "Integrate cultures and beliefs into genealogy software for remote communities in Borneo," in Proceedings of the International Conference on User Science and Engineering (i-USEr '11), pp. 222-227, Shah Alam, Malaysia, November-December 2011.

[6] T. Zaman, A. W. Yeo, and N. Kulathuramaiyer, "Augmenting indigenous knowledge management with information and communication technology," International Journal of Services, Technology and Management, vol. 19, no. 1-3, pp. 137-148, 2013.

[7] P. Lunde, The Secrets of Codes: Understanding the World of Hidden Messages, Pier 9, Murdoch Books, Sydney, Australia, 2009.

[8] L. Liebenberg, The CyberTracker Story, 2016, http://www.cybertracker.co.za.

[9] BBC, “BBC-Tribe-Penan,” March 2008, http://www.bbc.co.uk/ tribe/tribes/penan/index.shtml.

[10] W. Davis and T. Henley, Penan: Voice for the Borneo Rainforest, Western Canada Wilderness Committee-Wild Campaign, 1990.

[11] L. Curtis, “Borneo: Tong Tana-Walking with the Penan,” 2010, http://www.artquest.org.uk/uploads/recovered_files/Walking\% 20with\%20the\%20Penan\%20UoA\%20update[2].pdf.

[12] G. G. Gómez, "Computer technology and native literacy in the Amazon rain forest," in Information Technology And Indigenous People, L. E. Dyson, M. Hendriks, and S. Grant, Eds., pp. 117-119, Idea Group, Calgary, Canada, 2007. 
[13] S. Zagala, "Vanuatu sand drawing," Museum International, vol. 56, no. 1-2, pp. 32-35, 2004.

[14] SARC Communicator, Use Your iPhone To Send Smoke Signals, SARC Communicator, 2014.

[15] C. Vanderlip, "Silbo Gomero and Whistled Languages," 2013, http://scholarworks.gvsu.edu/ssd/2013/oral_visual/27/.

[16] N. L. Hoft, "Developing a cultural model," in International Users Interface, pp. 41-73, John Wiley \& Sons, 1996.

[17] N. W. Sheehan, "Indigenous knowledge and respectful design: an evidence-based approach," Design Issues, vol. 27, no. 4, pp. 68-80, 2011.

[18] G. K. Kapuire, H. Winschiers-Theophilus, C. Stanley et al., "Community-based co-design in Okomakuara a contribution to 'design in the wild"' in Proceedings of the 13th Participatory Design Conference: Short Papers, Industry Cases, Workshop Descriptions, Doctoral Consortium Papers, and KeynoteAbstracts (PDC '14), vol. 2, pp. 207-208, 2014.

[19] M. Niemelä, V. Ikonen, J. Leikas et al., "Human-driven design: a human-driven approach to the design of technology," in ICT and Society, pp. 78-91, Springer, Berlin, Germany, 2014.

[20] S.-T. Siew, A. W. Yeo, and T. Zaman, "Participatory action research in software development: indigenous knowledge management systems case study," in Human-Computer Interaction. Human-Centred Design Approaches, Methods, Tools, and Environments, pp. 470-479, Springer, Berlin, Germany, 2013.

[21] T. Zaman, A. W. Yeo, and N. Kulathuramaiyer, "Harnessing community's creative expression and indigenous wisdom to create value. Tacit-Implicit-Explicit (TIE) knowledge creation model," in Proceedings of the Embracing Indigenous Knowledge Systems in a New Technology Design Paradigm (IKTC '11), Windhoek, Namibia, 2011.

[22] E. Linden, "Lost tribes, lost knowledge," Time, pp. 46-56, 1991.

[23] R. Blagojevic and B. Plimmer, "CapTUI: geometric drawing with tangibles on a capacitive multi-touch display," in HumanComputer Interaction-INTERACT 2013, pp. 511-528, Springer, 2013.

[24] M. Bock, M. Fisker, K. F. Topp, and M. Kraus, "Initial exploration of the use of specific tangible widgets for tablet games," in Social Informatics, vol. 8852 of Lecture Notes in Computer Science, pp. 183-190, Springer, Berlin, Germany, 2015.

[25] B. Hengeveld, C. Hummels, K. Overbeeke, R. Voort, H. van Balkom, and J. de Moor, "Tangibles for toddlers learning language," in Proceedings of the 3rd International Conference on Tangible and Embedded Interaction, Cambridge, UK, February 2009.

[26] B. Plimmer, L. He, T. Zaman, K. Karunanayaka, A. W. Yeo, and G. Jengan, "New interaction tools for preserving an old language," in Proceedings of the 33rd Annual ACM Conference on Human Factors in Computing Systems (CHI '15), Seoul, Republic of Korea, April 2015.

[27] T. Zaman, H. Winschiers-Theophilus, A. W. Yeo, L. C. Ting, and G. Jengan, "Reviving an indigenous rainforest sign language: digital Oroo' adventure game," in Proceedings of the Seventh International Conference on Information and Communication Technologies and Development (ICTD '15), article 69, 2015.

[28] T. Zaman and A. Y. Wee, "Ensuring participatory design through free, prior and informed consent: a tale of indigenous knowledge management system," in User-Centric Technology Design for Nonprofit and Civic Engagements, pp. 41-54, Springer, 2014.
[29] D. Larsen-Freeman and D. Freeman, "Language moves: the place of 'foreign' languages in classroom teaching and learning," Review of Research in Education, vol. 32, no. 1, pp. 147-186, 2008. 

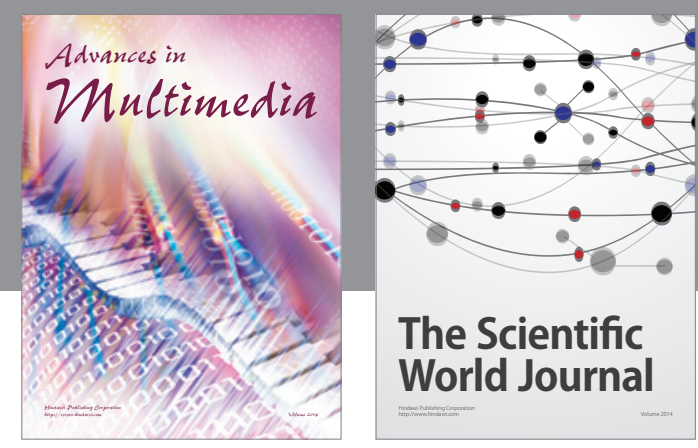

The Scientific World Journal
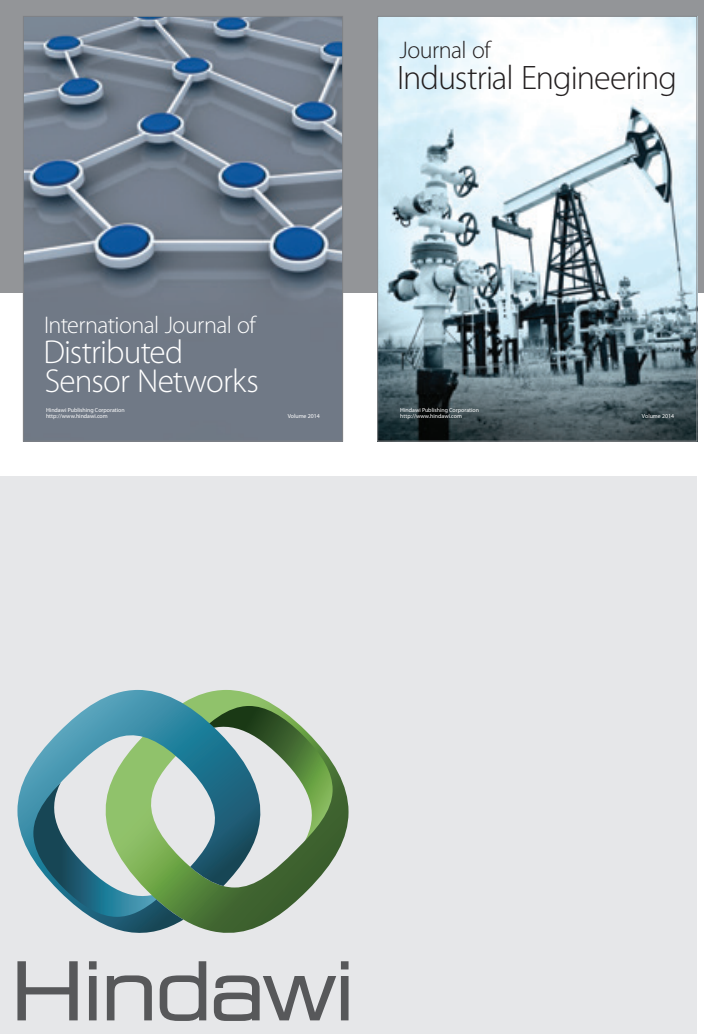

Submit your manuscripts at

http://www.hindawi.com

\section{Computer Networks} and Communications
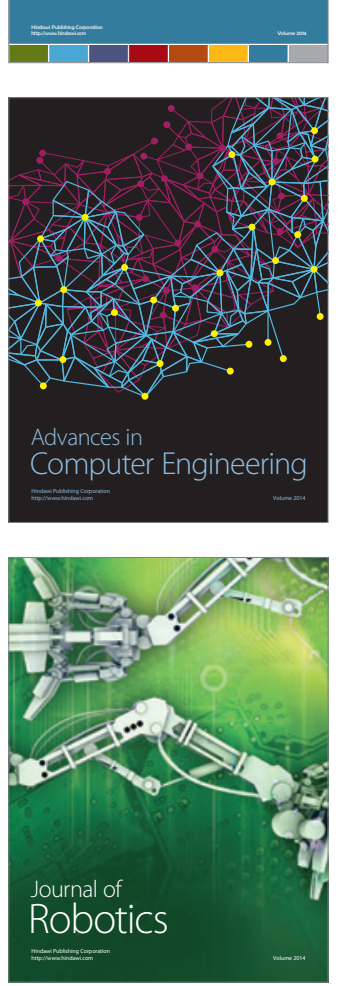
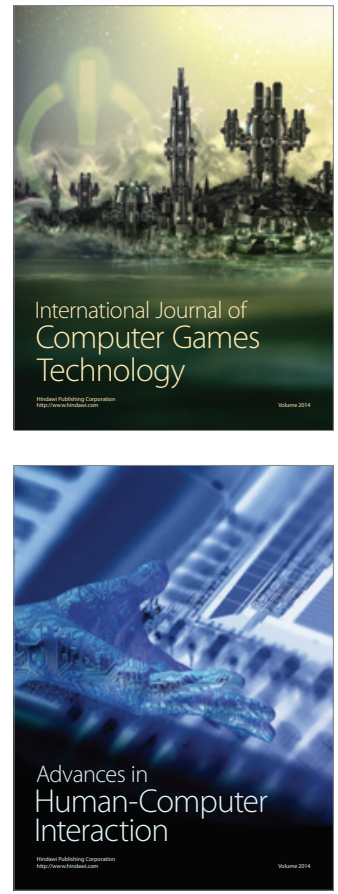
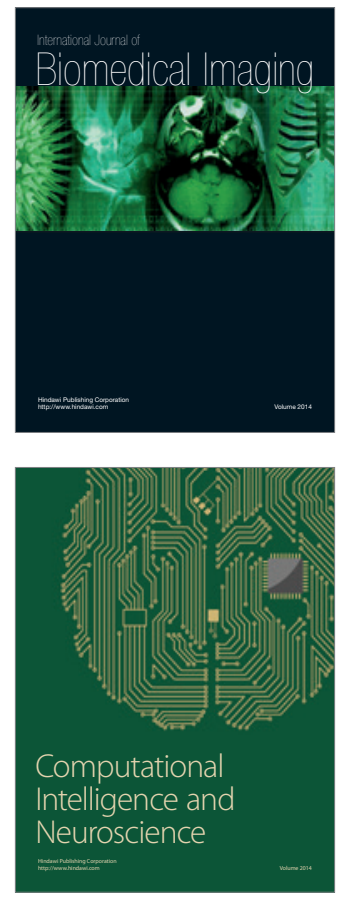
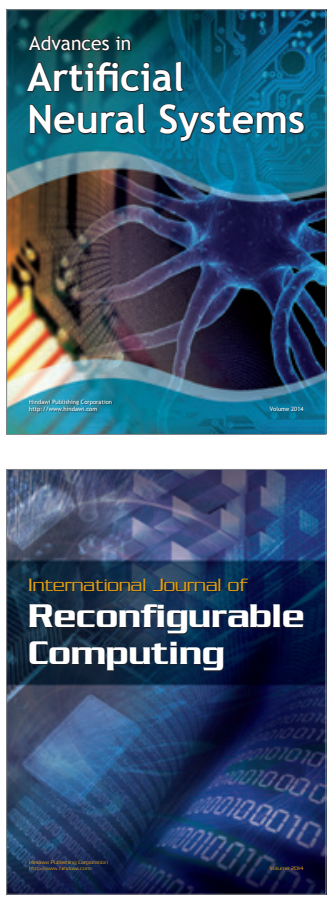
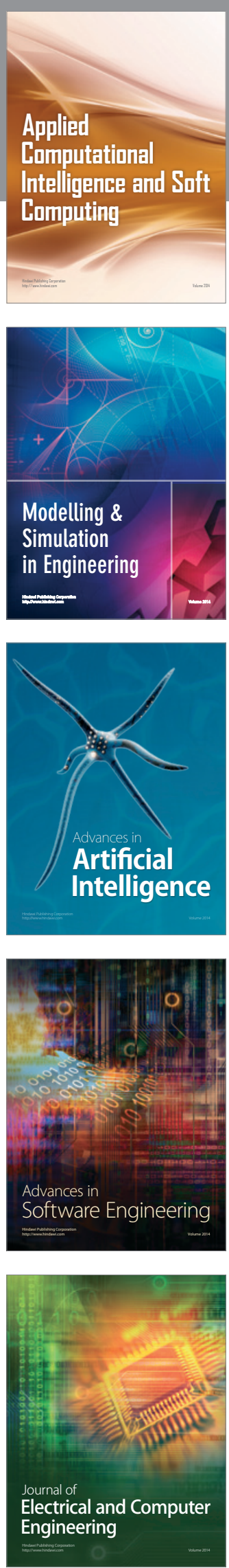